\title{
The CDC Healthy Aging Research Network: advancing science toward action and policy for the evidence-based health promotion movement
}

\author{
Basia Belza ${ }^{1,2}$, Mary Altpeter ${ }^{3}$, Steven P. Hooker ${ }^{4}$ and Gwen Moni ${ }^{1}$ \\ ${ }^{1}$ Department of Health Services, Health Promotion Research Center, University of Washington, Seattle, WA, USA \\ ${ }^{2}$ Department of Biobehavioral Nursing and Health Systems, Health Promotion Research Center, University of Washington, Seattle, WA, USA \\ ${ }^{3}$ Center for Health Promotion and Disease Prevention, University of North Carolina at Chapel Hill, Chapel Hill, NC, USA \\ ${ }^{4}$ School of Nutrition and Health Promotion, Arizona State University, Phoenix, AZ, USA \\ ${ }^{*}$ Correspondence: basiab@uw.edu \\ Edited by: \\ Matthew Lee Smith, The University of Georgia, USA \\ Reviewed by: \\ Heather Honoré Goltz, University of Houston-Downtown, USA
}

Keywords: evidence-based, dissemination, aging, networks, health promotion

Despite recent progress in the uptake of evidence-based health promotion (EBHP) programs within communities, many factors contribute to the need to focus on dissemination. These include the growth in the aging population, health care resource limitations, and interests in preserving community-based opportunities for maintaining independence and maximizing quality of life. For these reasons, The Prevention Research Centers' Healthy Aging Research Network (HAN), funded by the Centers for Disease Control and Prevention's (CDC's) Healthy Aging Program, has as its core mission, to translate effective healthy aging interventions into sustainable community-based programs. Researchers and community-based stakeholders collaborate across HAN's seven member center and two affiliate universities (Figure 1) to develop and implement health promotion programs for older adults at individual, organizational, environmental, and policy levels (1-3). This commentary highlights selected HAN contributions to the EBHP movement from 2001 to 2014. These contributions serve as examples of potential models for future partnership efforts to enhance implementation, dissemination, and sustainability of EBHP programs.

\section{WE BUILD THE FOUNDATION FOR EBHP PROGRAMS}

The HAN has engaged researchers and practitioners from multiple disciplines and community organizations. We use the principles of community-based participatory research in diverse communities to develop research priorities (4-10) and to build a knowledge base for EBHP programs (1114). Through these partnerships, HAN researchers have developed and tested practical tools and resources for the development, implementation and evaluation of interventions and frameworks (e.g., REAIM) for their dissemination and sustainability $(15,16)$.

For instance, HAN created and tested many of the programs described in this issue of Frontiers [i.e., EnhanceFitness, Chronic Disease Self-management Program (CDMSP), Fit and Strong! and Program to Encourage Active Rewarding Lives (PEARLS) (17-23)]. Nationally, we provided technical assistance on EBHP program implementation and evaluation for the Administration on Aging (within the Administration for Community Living) and grantee organizations. We have documented our methods of technical assistance in numerous peer-reviewed publications $(2,13,19,24,25)$.

An example of our regional efforts is reflected in the HAN's EBHP partnership with the Health Foundation of South Florida (HFSF) and Florida Healthy Aging Collaborative. HFSF is a not-forprofit grant-making organization with a focus on expanding access to affordable, quality healthcare for underserved populations in Florida's Broward, Miami-Dade, and Monroe counties. HFSF launched a tri-county, 5-year $\$ 7.6$ million health promotion and disease prevention initiative. HAN assisted with the initial planning and design of the initiative (e.g., program selection, evaluation components), helped launch workshops for prospective grantees, incorporated RE-AIM into the grant proposal structure, reviewed grant applications, and provided training materials for staff and grantees about RE-AIM. HAN also served on the leadership council and provided grantees with post-award technical assistance.

\section{WE ENHANCE CAPACITY}

To support the translation of EBHP programs into practice and policy, HAN has helped to enhance the capacity of researchers and practitioners. At the local, state, and national level, HAN has mentored and provided leadership opportunities for graduate students, early career investigators, and CDC Healthy Aging Program fellows by encouraging them to actively participate in HAN EBHP initiatives. Working with practice partners and national stakeholders, HAN has also built professional capacity by developing and delivering accessible, stateof-the-science trainings and resources. These include: conferences, online training modules (www.healthyagingprograms. org/content), monographs, and issue briefs about EBHP practice and various aspects of program delivery and quality assurance, physical activity, mental health, environment, and policy $(26,27)$.

Healthy Aging Research Network secured and leveraged a CDC conference grant to develop and deliver researchto-practice symposia on physical activity, 


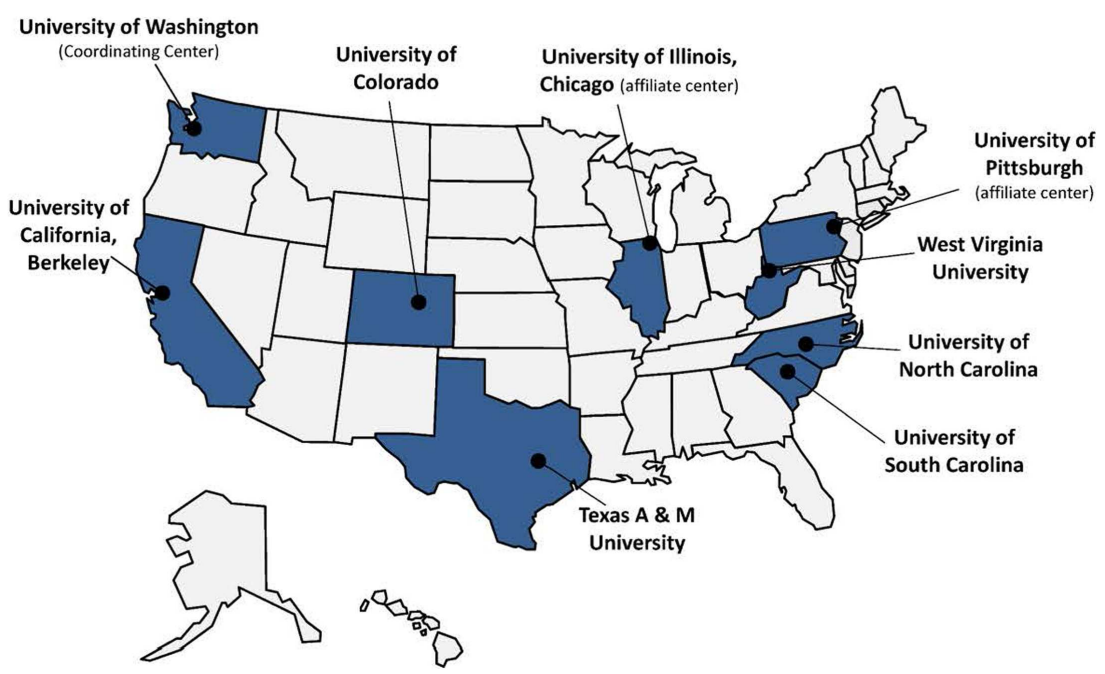

FIGURE 1 | CDC Healthy Aging Research Network (HAN) member centers and affiliates (FY 2009-2014)

mental health, and environmental policies. This series brought together national research and community partners to strategize how best to disseminate and sustain effective community-based programs and practices. For this series, HAN engaged new partners (e.g., AARP, The Carter Presidential Center, and the Rosalynn Carter Georgia Mental Health Forum, CDC Healthy Communities Program). HAN also secured additional funds from the Retirement Research Foundation to develop post-conference products and from the Agency for Healthcare Quality and Research to provide technical assistance. The ultimate result was the dissemination and uptake of a monograph (26), two coordinated and well-attended series of online webinars, as well as presentations and action briefs. HAN also contributed to the training of practitioners through presentations to the National Association of Chronic Disease Directors and National Association of State Units on Aging - Healthy Aging Initiative.

\section{WE AFFECT PRACTICE AND POLICY}

At the national level, the Task Force on Community Preventive Services published recommendations from a HAN investigator-led review of communitybased depression interventions on The Community Guide (28-32). This was the first time the Task Force accepted the findings of an "external" review. At the state level, HAN worked with the Washington State Unit on Aging to apply the recommendations to the agency's depression screening policy to utilize a validated depression screening measure in annual assessments of clients who receive services. As a result, the Area Agencies on Aging in Washington have a better understanding of what proportion of their clients are depressed. In addition, practitioners can use this screening measure to determine client eligibility for PEARLS, an evidence-based program for depression. Consequently, evidence-based procedures and programs are now integrated into this state's existing aging and social services.

In summary, HAN is the go-to source for technical assistance in large-scale EBHP program and policy design, implementation, and evaluation efforts with regional, national, and academic partners. HAN has harnessed the power and cost-effectiveness of multi-disciplinary, multi-site endeavors and become a recognized leader, able to convene disparate groups of stakeholders to build the science for EBHP. HAN investigators will continue to serve as facilitators and bridge builders to expand the overall public health and aging network within and outside of academia. Going forward, HAN investigators will continue to conduct EBHP research to improve capacity building, determine optimal methods for facilitating systems change in health promotion for older adults, and investigate the effectiveness of EBHP programs.

\section{ACKNOWLEDGMENTS}

We acknowledge our HAN members who have led and participated in the initiatives described in this commentary. The HAN is a Prevention Research Centers program funded by the CDC Healthy Aging Program. Efforts were supported in part by cooperative agreements from CDC's Prevention Research Centers Program: U48-DP-001911, 001908, 001921, 001924, 001936, 001938, and 001944. The findings and conclusions in this report are those of the authors and do not necessarily represent the official position of the Centers for Disease Control and Prevention or the Department of Health and Human Services.

\section{REFERENCES}

1. Hunter RH, Anderson LA, Belza B, Bodiford K, Hooker SP, Kochtitzky CS, et al. Environments for healthy aging: linking prevention research and public health practice. Prev Chronic Dis (2013) 10:E55. doi:10.5888/pcd10.120244

2. Lang JE, Anderson L, LoGerfo J, Sharkey J, Belansky E, Bryant L, et al. The prevention research centers Healthy Aging Research Network. Prev Chronic Dis (2006) 3(1):A17.

3. Wilcox S, Altpeter M, Anderson L, Belza B, Bryant L, Jones DL, et al. The Healthy Aging Research Network: building capacity for public health and aging practice. Am J Health Promot (2013) 28(1):206. doi:10.4278/ajhp.121116-CIT-564

4. Prohaska T, Belansky E, Belza B, Buchner D, Marshall V, McTigue K, et al. Physical activity, public 
health, and aging: critical issues and research priorities. J Gerontol B Psychol Sci Soc Sci (2006) 61(5):S267-73. doi:10.1093/geronb/61.5.S267

5. Hughes SL, Williams B, Molina LC, Bayles C, Bryant LL, Harris JR, et al. Characteristics of physical activity programs for older adults: results of a multisite survey. The Gerontologist (2005) 45(5):667-75. doi:10.1093/ geront $/ 45.5 .667$

6. Anderson L, Logsdon RG, Hochhalter AK, Sharkey JR. Introduction to the special issue on promoting cognitive health in diverse populations of older adults. The Gerontologist (2009) 49(S1):S1-2. doi:10.1093/geront/gnp073

7. Hughes SL, Leith KH, Marquez DX, Moni G, Nguyen HQ, Desai P, et al. Physical activity and older adults: expert consensus for a new research agenda (an Editor's Choice article). The Gerontologist (2011) 51(6):822-32. doi:10.1093/geront/ gnr106

8. Satariano WA, Guralnik JM, Jackson RJ, Marottoli RA, Phelan EA, Prohaska TR. Mobility and aging: new directions for public health action. Am J Public Health (2012) 102(8):1508-15. doi:10.2105/AJPH. 2011.300631

9. Sharkey JR, Locher J, Sahyoun N, Wilcox S. Nutrition and aging: nutritional health inequity (editorial). J Aging Res (2012) 2012:164106. doi:10.1155/ 2012/164106

10. Anderson LA, Day KL, Vandenberg AE. Using a concept map as a tool for strategic planning: the healthy brain initiative. Prev Chronic Dis (2011) 8(5):A117.

11. Brownson RC, Ballew P, Dieffenderfer B, HaireJoshu D, Heath GW, Kreuter MW, et al. Evidencebased interventions to promote physical activity: what contributes to dissemination by state health departments. Am J Prev Med (2007) 33(1):S66-78. doi:10.1016/j.amepre.2007.03.011

12. Frank J, Coviak C, Healy T, Belza B, Casado B. Addressing fidelity in evidence-based health promotion programs for older adults. J Appl Gerontol (2008) 27(4):4-34. doi:10.1177/109019811454 3007

13. Hughes SL, Seymour RB, Campbell RT, Whitelaw $\mathrm{N}$, Bazzarre T. Best-practice physical activity programs for older adults: findings from the national impact study. Am J Public Health (2009) 99(2):362-8. doi:10.2105/AJPH.2007.131466

14. Logsdon RG, McCurry SM, Pike KC, Teri L. Making physical activity accessible to older adults with memory loss: a feasibility study. The Gerontologist (2009) 49(Suppl 1):S94-9. doi:10.1093/geront/ gnp082

15. Glasgow RE, Vogt TM, Boles SM. Evaluating the public health impact of health promotion interventions: the RE-AIM framework. Am J Public Health (1999) 89(9):1322-7. doi:10.2105/AJPH. 89.9.1322

16. Harris JR, Cheadle A, Hannon PA, Forehand M, Lichiello P, Mahoney E, et al. A framework for disseminating evidence-based health promotion practices. Prev Chronic Dis (2012) 9:110081. doi: 10.5888/pcd9.110081

17. Belza B, Shumway-Cook A, Phelan E, Williams B, Snyder S, LoGerfo J. The effects of a community-based exercise program on function and health in older adults: the EnhanceFitness program. J Appl Gerontol (2006) 25(4):291-306. doi:10.1177/0733464806290934

18. Belza B, Snyder S, Thompson M, LoGerfo J. From research to practice: EnhanceFitness ${ }^{\circledR}$, an innovative community-based senior exercise program. Top Geriatr Rehabil (2010) 26(4):299-309. doi:10. 1097/TGR.0b013e3181fee69e

19. Smith ML, Belza B, Altpeter M, Ahn S, Dickerson JB, Ory M. Disseminating an evidencebased disease self-management program for older Americans: implications for diversifying participant reach through delivery site adoption. In: Maddock J, editor. Public Health - Social and Behavioral Health. Rijeka: InTech - Open Access Publisher (2012). p. 385-404. doi:10.5772/36728

20. Hughes SL, Seymour RB, Campbell RT, Huber G, Pollak N, Sharma L, et al. Long term impact of Fit and Strong! on older adults with osteoarthritis. The Gerontologist (2006) 46(6):801-14. doi:10. 1093/geront/46.6.801

21. Etkin CD, Prohaska TR, Harris BA, Latham N, Jette A. Feasibility of implementing the Strong for Life program in community settings. The Gerontologist (2006) 46(2):284-92. doi:10.1093/geront/ 46.2.284

22. Steinman L, Cristofalo M, Snowden M. Implementation of an evidence-based depression care management program (PEARLS): perspectives from staff and former clients. Prev Chronic Dis (2012) 9:110250. doi:10.5888/pcd9.110250

23. Steinman L, Hammerback K, Snowden M. It could be a pearl to you: exploring recruitment and retention of the Program to Encourage Active, Rewarding Lives (PEARLS) with hard-to-reach populations. The Gerontologist (2013). doi:10.1093/ geront/gnt137

24. Bryant LL, Altpeter M, Whitelaw NA. Evaluation of health promotion programs for older adults: an introduction. J Appl Gerontol (2006) 25(3):197-213. doi:10.1177/0733464806288562

25. Smith ML, Ory MG, Belza B, Altpeter M. Personal and delivery site characteristics associated with intervention dosage in and evidence-based fall risk reduction program for older adults. Transl Behav Med (2012) 2:188-98. doi:10.1007/s13142012-0133-8

26. Belza B. PRC-HAN Physical Activity Conference Planning Workgroup. Moving Ahead: Strategies and Tools to Plan, Conduct, and Maintain Effective Community-Based Physical Activity Programs for Older Adults. Seattle, WA: (2007). Available from: http://depts.washington. edu/hprc/older-adults-primer/monograph.pdf

27. Belza B, Glasgow R, Toobert D. RE-AIM for Program Planning: Overview and Applications. Washington, DC: National Council on Aging (2007).

28. Guide to Community Preventive Services. Improving Mental Health and Addressing Mental Illness. (2014). Available from: http://www.the communityguide.org/mentalhealth/index.html

29. Frederick JT, Steinman LE, Prohaska T, Satariano WA, Bruce M, Bryant L, et al. Communitybased treatment of late life depression an expert panel-informed literature review. Am J Prev Med
(2007) 33(3):222-49. doi:10.1016/j.amepre.2007. 04.035

30. Steinman LE, Frederick JT, Prohaska T, Satariano WA, Dornberg-Lee S, Fisher R, et al. Recommendations for treating depression in community-based older adults. Am J Prev Med (2007) 33(3):175-81. doi:10.1016/j.amepre.2007.04.034

31. Snowden M, Steinman L, Frederick J. Treating depression in older adults: challenges to implementing the recommendations of an expert panel. Prev Chronic Dis (2008) 5(1). Available from: http: //www.cdc.gov/pcd/issues/2008/jan/07_0154.htm 32. Snowden M, Steinman L, Frederick J, Wilson N. Screening for depression in older adults: recommended instruments and considerations for community-based practice. Clin Geriatr (2009). Available from: http://www.consultant360.com/ articles/screening-depression-older-adultsrecommended-instruments-and-considerationscommunity

Conflict of Interest Statement: The authors declare that the research was conducted in the absence of any commercial or financial relationships that could be construed as a potential conflict of interest.

This paper is included in the Research Topic, "EvidenceBased Programming for Older Adults." This Research Topic received partial funding from multiple government and private organizations/agencies; however, the views, findings, and conclusions in these articles are those of the authors and do not necessarily represent the official position of these organizations/agencies. All papers published in the Research Topic received peer review from members of the Frontiers in Public Health (Public Health Education and Promotion section) panel of Review Editors. Because this Research Topic represents work closely associated with a nationwide evidence-based movement in the US, many of the authors and/or Review Editors may have worked together previously in some fashion. Review Editors were purposively selected based on their expertise with evaluation and/or evidence-based programming for older adults. Review Editors were independent of named authors on any given article published in this volume.

Received: 15 June 2014; accepted: 12 November 2014; published online: 27 April 2015.

Citation: Belza B, Altpeter M, Hooker SP and Moni $G$ (2015) The CDC Healthy Aging Research Network: advancing science toward action and policy for the evidence-based health promotion movement. Front. Public Health 2:261. doi: 10.3389/fpubh.2014.00261

This article was submitted to Public Health Education and Promotion, a section of the journal Frontiers in Public Health.

Copyright $\odot 2015$ Belza, Altpeter, Hooker and Moni. This is an open-access article distributed under the terms of the Creative Commons Attribution License (CC BY). The use, distribution or reproduction in other forums is permitted, provided the original author (s) or licensor are credited and that the original publication in this journal is cited, in accordance with accepted academic practice. No use, distribution or reproduction is permitted which does not comply with these terms. 